\title{
Development of a technology for producing ceramic refractory material in a composition of montmorillonite clays (bentonite- like) and ferrochrome production wastes
}

\author{
Sarsenbek Montayev ${ }^{1 *}$, Bekbulat Shakeshev ${ }^{1}$, and Sabit Zharylgapov ${ }^{1}$ \\ ${ }^{1}$ Zhangir khan university, 51 Zhangir khan str. Uralsk, Kazakhstan
}

\begin{abstract}
Annotation. The article presents the results of scientific and experimental studies on the creation of ceramic refractory material. Montmorillonite clay (bentonite-like) of the Pogodaevsky deposit and ferro-dust from selfdecaying slags of low-carbon ferrochrome of the Aktobe ferroalloy plant were selected as the most effective types of raw materials in terms of their physico-mechanical properties and chemico-mineralogical composition. The composition of ceramic mass in chamotte - ferro dust - binder and rational technological parameters of molding, drying and firing was developed. The basic physical and mechanical properties of the obtained ceramic samples, which have high strength, average density, low linear thermal expansion coefficient and fire shrinkage, are studied. Ceramic samples based on the proposed raw material composition can withstand temperatures up to $1350 \mathrm{C}$, which is 200-300 C higher than ceramic samples based on clay raw materials. The high strength indices and refractoriness of samples are explained by the fact that in result of heat treatment of the studied ceramic composition, a densely sintered framework with reinforced refractory minerals such as forsterite $\mathrm{Mg} 2(\mathrm{SiO} 4)$ and spinel $(\mathrm{MgAl} 2 \mathrm{O} 4)$ is formed. The prospects of this research area are associated with the creation of innovative technologies for the production of popular refractory materials, but also with an environmental issue. Processing of technogenic resources of Kazakhstan will not only reduce the consumption of natural resources, but also reduce the human impact on the environment.
\end{abstract}

\section{Introduction}

Currently, Kazakhstan is successfully implementing the state program of industrial and innovative development. In the process of implementing this program, new facilities are being introduced for the production of cement, lime, expanded clay, ceramic bricks, and also metallurgical enterprises are expanding. The development of these industries is inextricably linked with the consumption of refractory materials for lining thermal units, without which it is impossible to produce products.

To meet these needs, the Republic of Kazakhstan imports refractory materials for these enterprises from Russia, Ukraine, China, Austria and other countries.

The high demand for new high-quality refractory materials is also due to the steady increase in their consumption at existing metallurgical plants, as well as in the production of building materials, the technological process of which requires high-temperature firing (1100-14000C).

A preliminary analysis of the types of refractory materials consumption in the Republic of Kazakhstan showed that basically stable demand exists for refractory bricks and tiles, ramming materials, masonry mortars.

In this regard, the development of domestic production of refractories is one of the urgent and strategic tasks of the Republic of Kazakhstan.

The main key factors in the development of domestic production of refractories is the analysis of the availability of natural and technogenic raw materials and their assessment, as well as the development of innovative technologies for their production regarding improving quality, resource and energy conservation.

At the same time, a differentiated approach to each enterprise-consumer is necessary, given their high-temperature production processes and the design of thermal units. According to A.I. Khlystova [1], there is no universal refractory material that meets the requirements of working at high temperatures, with thermal shock, in liquid and gaseous aggressive environments and suitable for all cases of factory practice.

The studies of the authors [2-8] are devoted to solving issues related to the development of effective technologies for refractory materials that can provide future production industries.

\footnotetext{
* Corresponding author: montaevs@mail.ru
} 
Scientific research has special interest on recycling of battlefield of refractory products formed during repairs of thermal units (furnaces, converters, boilers, etc.) [9].

This is due to lack of refractory factories in Kazakhstan, therefore, enterprises for the production of building materials, the metallurgical industry and the power system located in the country are experiencing a shortage of it. For example, only one plant for the production of lime of JSC "West Kazakhstan Corporation of Building Materials" annually purchases over 50 tons of refractory materials abroad for repair and lining of rotary kilns. In the process, spent refractory materials are thrown into dumps as a waste.

Moreover, the experience of industrialized countries shows that the refractory brick battle is an excellent secondary raw material in the production of piece goods (bricks), as well as unformed refractories (refractory concrete, shotcrete, packed masses and dry mixes, refractory mortars, etc.) The use of battle of refractory products is effective both from an economic and environmental point of view [9].

At the current stage, we are familiar with earlier research works of scientists whose aim was to develop a technology for producing refractory materials using various natural raw materials and industrial waste. Relying on the results of undertaken investigations, unique system-based refractory ceramics were invented. To be specific, the $\mathrm{MgO}-\mathrm{ZrO} 2$ system were used on the basis of secondary magnesia-carbon brick [10] and high-quality refractory ceramics using oil sludge and bauxite raw materials [11] The given work [12] presents the results of the mentioned investigations on the development of a technology for producing refractory material based on alkali-activated refractory chamotte waste and from the alumina-zirconia-silicon dioxide. The given research work also contains determined possibility of obtaining refractory cellular concrete based on a phosphate binder from waste from the production and processing of aluminium [13].The effectiveness of the use of ferrochromic slag for the production of refractory materials, including high-strength refractory ceramics, has been proved by scientists' researches [14 -18].

An analysis of research by leading scientists shows that further development of the production of ceramic and refractory materials is inextricably linked with the improvement of existing technological processes with the development of new compositions based on technogenic and natural raw materials systems in order to improve energy efficiency and quality of the finished product $[19,20]$.

Enterprises in Kazakhstan that produce various products under the conditions of operation of thermal units at a temperature of 1000-12500C receive the most dynamic development. (production of ceramic bricks, lime, expanded clay, etc.).

Generally, those enterprises function almost in all areas of the country. That is why, the sintered refectories related to the rough ceramics technology are the most interesting, from the point of view of the rapid scientific developments realization in the existing enterprises.

Sintered refractories are successfully used for the construction of industrial furnaces and apparatuses operating at high temperatures (1000-1800 C). The products of sintered refractories, except refractoriness, provide not only strength at high temperature, but also heat and chemical resistance.

Analysis of refractory products that are delivered to Kazakhstan has showed that chamotte products are in high demand by the market. They make up about $75 \%$ of all refractories used in the country. In this case, the main types of refractory materials are refractory bricks, extruded shaped refractory products made by ceramic technology.

\section{Goals and objectives of the study}

Therefore, the goal of our study is to select raw materials from natural and technogenic resources of Kazakhstan and conduct scientific and experimental work on the development of ceramic compositions to establish the possibility of obtaining refractory ceramic material.

To achieve this goal, it is necessary to solve the following tasks:

- to select of the most effective types of raw materials according to their physical and mechanical properties and chemical and mineralogical composition;

-to develop of the most rational technological solutions for the preliminary preparation of raw materials with the aim of compiling a refractory ceramic composition;

- to conduct scientific and experimental work on the creation of refractory ceramic samples by dosing, mixing, molding, drying and firing.

\section{Materials and techniques}

High interest consists in creating composite refractory ceramic materials such as bentonite clays, ashes of thermal power plants (TPPs), metallurgical slag, and waste refractory materials which are generated during the repair and dismantling of the lining of high-temperature metallurgical and heat power units.

In this paper, to develop ceramic composition in order to obtain refractory materials, the following natural and technogenic resources of Kazakhstan were evaluated and studied: 
1. Montmorillonite (bentonite-like) clay Pogodaevskoye deposit (Western Kazakhstan) was chosen as natural raw material;

2. Ferro-dust from self-decaying slags of low-carbon ferrochrome of Aktobe ferroalloy plant was chosen as technogenic raw materials.

The selected raw materials are located in one region of Kazakhstan, which creates favorable technical and economic conditions for their processing and organization of the construction of a workshop for the production of ceramic refractory material.

At the initial stage of the research, the total reserves of the selected raw materials were specified. A study of the geological exploration revealed that the reserves of Pogodaevsky deposit of montmorillonite (bentonite-like) clays amount to more than 6181 thousand $\mathrm{m}^{3}$.

According to the statistic data of Aktobe ferrochrome plant, the annual output of ferro-dust is 1.5 thousand tons per year.

The studies on refractoriness of montmorillonite (bentonite-like) clay in Pogodaevskoye deposit have shown that its refractoriness is in the range of (1200-1250 C).

The chemical and mineralogical composition of studied raw materials was determined using a JSM-6390LV scanning electron microscope with an energy-dispersive microanalysis system, an X'Pert PRO MPD X-ray diffractometer, and an ICP-MS Agilent 7500cx inductively coupled plasma mass spectrometer (JEOL, Japan) Fig. 1.

X-ray phase analysis (XRD) was carried out on a DRON-3 diffractometer with SiKa- radiation in the range of angles 80 640. The sensitivity of method is from 1 to $2 \%$. The powder of the studied raw materials passed through a 0.315 sieve was subjected to X-ray phase analysis.

The chemical composition of montmorillonite clay (bentonite-like) is presented in Table 1.

Table 1. The chemical composition of montmorillonite clay (bentonite-like) Pogodaevsky deposits.

\begin{tabular}{|c|c|c|c|c|c|c|c|c|}
\hline & \multicolumn{7}{|c|}{ Oxide content, mass \% } & Name of raw material \\
\cline { 2 - 9 } & $\mathrm{SiO}_{2}$ & $\mathrm{Al}_{2} \mathrm{O}_{3}$ & $\mathrm{CaO}$ & $\mathrm{MgO}$ & $\mathrm{Fe}_{2} \mathrm{O}_{3}$ & $\mathrm{SO}_{3}$ & $\mathrm{Na}_{2} \mathrm{O}$ & $\begin{array}{c}\text { Lost on } \\
\text { ignition }\end{array}$ \\
\hline $\begin{array}{c}\text { Montmorillonite clay } \\
\text { (bentonite-like) }\end{array}$ & 61.51 & 17.06 & 2.27 & 3.21 & 6.36 & 1.27 & 3.57 & 6.75 \\
\hline
\end{tabular}

\section{Results and discussion}

According to the results of x-ray phase analysis, it was found that the mineralogical composition of montmorillonite clay (bentonite-like) in Pogodaevsk deposit is represented mainly by montmorillonite $(\mathrm{d} / \mathrm{n}=5.06 ; 4.46 ; 3.79 ; 3.06 ; 2.455 ; 2.28$; 2.127; $1.977 ; 1.817 ; 1.675 * 10-10 \mathrm{~m}$.)

Ferro dust from self-decaying slags of low-carbon ferrochrome of Aktobe ferroalloy plant is a finely divided gray powder. When sifting on a sieve with a mesh of $0.5 \mathrm{~mm}$, the residue is not more than $0.2 \%$.

The results of the study on their chemical and mineralogical composition and microstructure are presented in Table 2 and in Fig. 1.

Table 2. Chemical composition of dust from self-decaying slag low-carbon ferrochrome of the Aktobe ferroalloy plant.

\begin{tabular}{|l|l|l|l|l|l|l|l|l|l|l|}
\hline Name of raw material & \multicolumn{10}{c|}{ Oxide content, mass \% } \\
\cline { 2 - 11 } & $\mathrm{Cr}_{2} \mathrm{O}_{3}$ & $\mathrm{CaO}$ & $\mathrm{MgO}$ & $\mathrm{Al}_{2} \mathrm{O}_{3}$ & $\mathrm{FeO}$ & $\mathrm{SiO}_{2}$ & $\mathrm{Na}_{2} \mathrm{O}$ & $\mathrm{K}_{2} \mathrm{O}$ & $\mathrm{TiO}_{2}$ & $\mathrm{Mn}$ \\
\hline Ferroalloy & 2.001 & 2.07 & 29.2 & 15.91 & 1.29 & 18.8 & 0.51 & 0.2 & 0.36 & 0.10 \\
& 2.75 & 2.84 & 40.3 & 21.89 & 1.77 & 25.9 & 0.70 & 0.3 & 0.49 & 0.13 \\
\hline
\end{tabular}

According to the results of chemical-mineralogical and electron-microscopic studies, as well as X-ray diffraction (XRD) analysis, it was found that the studied ferro dust is represented by spinel (MgAl2O4) (d, $\AA$ : 4.69-3.73-2.87-2.45-2.021.431); forsterite $(\mathrm{Mg} 2(\mathrm{SiO} 4))$ (d, $\AA$ : 5.107-3.882-3.491-2.762-2.349-2.263-2.158-1.747-1.495-1.392); magnetite (Fe3O4) (d, Å: 3.00-2.51-2.11-1.616-1.565.1.476). Thus, it can be argued that the mineral and phase composition is mainly represented by forsterite and spinel, which are the main minerals of refractory materials. 


\begin{tabular}{|c|c|c|}
\hline Element & Weight \% & Atomic \% \\
\hline $\mathrm{O}$ & 45.52 & 59.72 \\
\hline $\mathrm{Na}$ & 0.41 & 0.38 \\
\hline $\mathrm{Mg}$ & 20.45 & 17.66 \\
\hline $\mathrm{Al}$ & 10.82 & 8.42 \\
\hline $\mathrm{Si}$ & 11.81 & 8.82 \\
\hline $\mathrm{S}$ & 0.70 & 0.46 \\
\hline $\mathrm{Cl}$ & 0.27 & 0.15 \\
\hline $\mathrm{K}$ & 0.43 & 0.23 \\
\hline $\mathrm{Ca}$ & 2.83 & 1.48 \\
\hline $\mathrm{Ti}$ & 0.48 & 0.22 \\
\hline $\mathrm{Cr}$ & 3.39 & 1.37 \\
\hline $\mathrm{Mn}$ & 0.19 & 0.08 \\
\hline $\mathrm{Fe}$ & 2.70 & 1.01 \\
\hline $\mathrm{Total}$ & 100.00 & \\
\hline
\end{tabular}

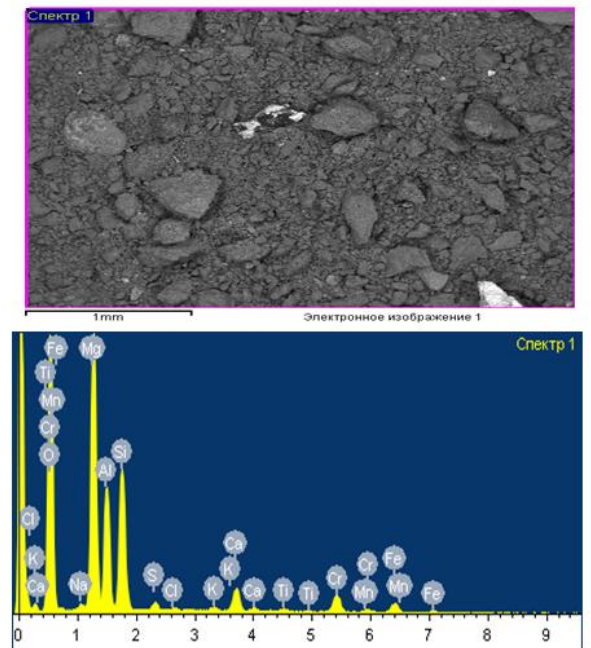

Fig. 1. Elemental composition, microstructure, and spectra of dust from self-decaying slags of low-carbon ferrochrome of the Aktobe ferroalloy plant.

To determine the refractoriness of the ferro dust, the samples were fired in an electric furnace until the onset of deformation. According to the results of experimental work, the refractoriness of ferro dust was established, which is 1300$13500 \mathrm{C}$.

The ratio $(\mathrm{CaO}+\mathrm{MgO}) /(\mathrm{SiO} 2+\mathrm{Al} 2 \mathrm{O} 3)$ is $1.7-1.9$, which makes ferrous dust highly basic. The indicated properties of the dust will increase the heat resistance of refractory materials.

Scientific and experimental work was carried out in the following sequence:

- development of compositions and technology for producing chamotte based on montmorillonite (bentonite-like) clay;

- development of the composition of the ceramic mass in the chamotte - ferro-dust - binder system;

- development of technological parameters of molding, drying and firing of the ceramic composition in order to obtain refractory material.

To achieve the maximum degree of mullitization during the clay firing process, the optimal compositions of the ceramic composition in the system of montmorillonite clay - ferro-dust from self-decaying slags to produce fireclay have been developed. To obtain chamotte based on a optimal composite raw material mixture, the montmorillonite clay was first dried in an oven (ШСП-0,5-70) at a temperature of 100-1100C to a residual moisture content of 5-7\%. Then, the dried montmorillonite clay was crushed in a laboratory jaw crusher (DS 80150) to obtain a fraction of $\geq 30 \mathrm{~mm}$. Then, crushed montmorillonite clay and ferro dust from self-decaying slags were dosed in the ratio 1: 2 and loaded into a laboratory ball mill.

The raw material composition was subjected to joint grinding in order to homogenize and to be mechanically activated until they pass through a 0.315 sieve. The thus obtained powders were used for two purposes. One part was used as raw material for the production of chamotte, and the other part as a binder component in the formation of samples.

The first part of the obtained powder was used in order to get chamotte in the following way: a ceramic mass was prepared with a moisture content of $25-27 \%$ and granules with a diameter of $10-20 \mathrm{~mm}$ were formed. Then they were put to dry in an oven to get residual moisture content of $5-7 \%$.

The dried granules were fired in a laboratory rotary furnace (RSR120 / 1000/13 Germany) at a temperature of $1250{ }^{\circ} \mathrm{C}$ with an exposure, at a maximum temperature, for 2 hours.

The burnt granules were crushed once again in a laboratory jaw crusher and sieved through a set of sieves. Thus, chamotte of various fractions was obtained. Fractions of 1.0-3.0 mm chamotte were selected for scientific and experimental work, because according to the results of preliminary experimental work these fractions showed the most optimal properties at the stage of molding, drying and firing.

In order to form raw samples of refractory material, a raw mixture was prepared in the chamotte-binder system. The second part of the finished powder which was obtained by co-grinding of montmorillonite clay and ferro-dust from selfdecaying slags in a laboratory ball mill was used as a binder. It should be noted that this mixture has a plasticity number of 12-15 due to the high amount of plastic montmorillonite clay in it, which ensures reliable adhesion of polyfraction chamotte particles.

The optimal amount of binder accounted for $10-12 \%$ of the total weight of chamotte.

The total content of ferrous dust in the composition is $88-90 \%$. The raw material mixture from the ceramic composition in the chamotte-binder system was thoroughly mixed in a spherical bowl with the addition of water in an amount of 8-10\% and cylinder samples $(50 \times 50 \times 50 \mathrm{~mm})$ were formed by semi-dry pressing. The pressing pressure was $20 \mathrm{MPa}$. The molded 
samples were fired without preliminary drying in a muffle electric furnace (SNOL 80/12) according to a specially developed mode. The maximum firing temperature was $1200 \mathrm{C}$.

The heat-treated samples were cooled in a disconnected furnace to room temperature and were tested to determine the physical and mechanical properties. Physico-mechanical properties of the studied samples are presented in Table.3.

Table 3. Physico-mechanical properties of the samples.

\begin{tabular}{|l|c|c|}
\hline \multicolumn{1}{|c|}{ Properties } & Unit of measurement & Indicators \\
\hline Average density & $\mathrm{kg} / \mathrm{m}^{3}$ & $2200-2250$ \\
\hline Compressive strength & $\mathrm{MPa}$ & $15.5-16.7$ \\
\hline Fire shrinkage & $\%$ & $0.18-0.21$ \\
\hline Thermal extension coefficient & $10^{-6} \mathrm{C}^{-1}$ & $3.1-3.3$ \\
\hline Temperature at the initial deformation & ${ }^{0} \mathrm{C}$ & 1350 \\
\hline
\end{tabular}

The test results of the physicomechanical properties of the samples show that the samples obtained on the basis of the studied raw material composition have the required compressive strengths. The strength of the calcined samples is $15.5-16.7$ $\mathrm{MPa}$. In addition, the samples are characterized by low rates of fire shrinkage of $-0.18-0.21 \%$. The samples have a densely sintered structure, which is confirmed by high average density indices $-2200-2250 \mathrm{~kg} / \mathrm{m} 3$. Ceramic samples based on the proposed raw material composition can withstand temperatures up to $13500 \mathrm{C}$, which is $200-3000 \mathrm{C}$ higher than ceramic samples based on clay raw materials. The high strength characteristics and refractoriness of the samples are explained by the fact that in result of heat treatment of the studied ceramic composition, a densely sintered frame with reinforced refractory minerals such as forsterite $\mathrm{Mg} 2(\mathrm{SiO} 4)$ and spinel $(\mathrm{MgAl} 2 \mathrm{O} 4)$ is formed.

\section{Conclusion}

- The montmorillonite clay (bentonite-like) of Pogodaevsky deposit and ferro-dust from self-decaying slags of low-carbon ferrochrome of Aktobe ferroalloy plant were selected as the most effective types of raw materials in terms of their physical and mechanical properties and chemical and mineralogical composition in order to obtain ceramic refractory material;

- It was found that the studied raw materials are representing a valuable resource for the production of refractory ceramic materials.

- Compositions and technologies for producing the chamotte were developed based on montmorillonite (bentonite-like) clay in order to increase the content of refractory crystalline phases;

- The composition of the ceramic mass was developed in the chamotte system - ferro-dust - binder and rational technological parameters of molding, drying and firing the ceramic composition in order to obtain a refractory material;

- The basic physical and mechanical properties of the obtained ceramic samples were studied. It was found that those ceramic samples have the high strength, average density and low linear thermal expansion coefficient and fire shrinkage;

- It was found that the obtained ceramic products based on the developed composition may well satisfy the requirements for lining thermal units with a working temperature of up to $13000 \mathrm{C}$.

- The prospects of this research area are associated not only with the creation of domestic technology for the production of refractory materials, but also with the environmental issue of the utilization of industrial waste. Processing of technogenic resources of Kazakhstan will not only reduce the consumption of natural resources, but also reduce the human impact on the environment.

\section{References}

1. A.I Khlystov, Improving Efficiency and Improving the Quality of Refractory Lining Materials 134 p. (Monograph, Samarsk. state arch. - builds. un-t, 2004)

2. I.V. Gladkih, E.P. Volynkina, The methodology for assessing the quality of industrial raw materials in the production of refractory and heat-insulating materials for metallurgy 10, 42-45 (University proceedings. Ferrous metallurgy, 2011)

3. A. T. Volochko, K. B. Podbolotov, E. M. Dyatlova, Refractory and refractory ceramic materials 385 p., ISBN $978-$ 985-08-1640-5 (Minsk: Belarus, Navuka, 2013)

4. V.A. Kononov, Bull. "Ferrous metallurgy" 6, 33-43(2001)

5. L.B. Khoroshavin, V.A. Perepelitsin, Refract. Ind. Ceram., 4, 43-47 (2000)

6. Yu .E. Pivinsky, Refract. Ind. Ceram., 1, Part 1, 11-16 (2000) 
7. L. M. Axelrod, et al., Bull. of USTU, 1, 60-66 (Physicochemistry and technology of oxide-silicate materials, Ekaterinburg. Publishing house of USTU, 2000)

8. A. Nukhuly, B.N. Satbaev, A.K. Svidersky, Bull. of the Innovative Eurasian University, 2, 158-164 (2007)

9. K.A. Cherepanov, S.M. Abramovich, M.V. Temlyandrov, E.N. Temlyandeva, Recycling of solid waste in metallurgy, 212 p. (Moscow: Flint Science, 2004)

10. R. Kusiorowski, Constr. Build. Mater., 231,117084 (20 January, 2020)

11. N.M. Khalil, Y.Algama. 1. Qayid, M. Saleem, Exploitation of petroleum waste sludge with local bauxite raw material for producing high-quality refractory ceramics, Ceram. Int., 44 (15), 18516-18527 (15 October, 2018)

12. B. Coppola, C.Tardivat, S. Richaud, Jean-Marc Tulliani, L. Montanaro, P. Palmero, J. Eur. Ceram. Soc. (February, 2020)

13. V.A. Abyzov, Procedia Eng., 206, $783-789$ (2017)

14. Pattem Hemanth, Kumar Abhinav. Srivastava Vijay, Kumar Vinay, Kumar Singh, J. Asian Ceram. Soc., 2 (4), $371-379$ (2014)

15. Yuhan Ren, Qiang Ren, Xiulan Wu, Jinle Zheng, Ou Hai, Recycling of solid wastes ferrochromium slag for preparation of eco-friendly high-strength spinel-corundum ceramics, Mater. Chem. Phys., 239, 1220601 (2020)

16. Kumar Hemanth, Srivastava Abhinav, Kumar Vijay, Ranjan Manas, Kumar Majhi Vinay, J. Asian Ceram. Soc., 2 (2), 169-175 (2014)

17. Vusumuzi Sibanda, Refilwe Kopong, Sehliselo Ndlovu, Ratombo Zwanga, Int. J. Miner. Process., 157,46-54 (2016)

18. Rundong Fan, Huizhong Zhao, Han Zhang, Pengda Zhao, Jianwei Chen, Xianghui Wang, Ceram. Int., .45 (9), $11204-$ 11215 (2019)

19. S.A. Montayev, Zh.T. Suleimenov, Wall ceramics based on compositions of technogenic and natural raw materials of Kazakhstan 157 p. (Monograph., Almaty: Gylym, 2006)

20. K.A. Cherepanov, S.M. Abramovich, M.V. Temlyard, E.N. Temlyandeva, Solid Waste Recycling in Metallurgy 212 p. (Moscow: Flint - Science, 2004) 